\title{
Wo $\mathfrak{i} \mathfrak{w} \mathfrak{a} \mathfrak{r}$.
}

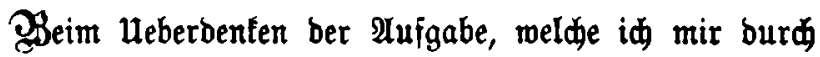
ben Entidlus itellte, ein „populäres” Bud über bas Sifrolfop zu idreiben, fonnte ez mir nidht zweifel=

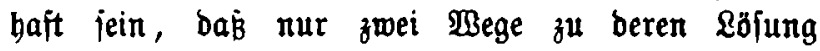
fübrten. Entweber trat id in bie Fustapien ber

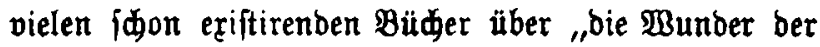
unfiditbaren Bclt", welde bem Sejer eill Raleibojifop non allerlei bunten un's zierídjen, vermunberliđen und ungebeuerliden (Bejtalten vorfübren und aljo eime 2 rrt von mifroffopiider Taujend $=$ unb $=$ eine $=$ Radit barftellen,

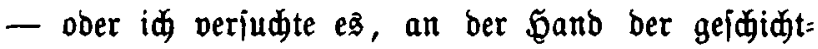
lidien uno miffenidiaftliden Thatiaden ein Bild bez Jnitrumentes und feiner Reiftungent zu entrollen, weldes

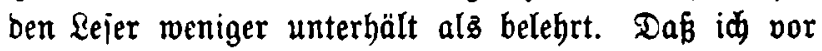
einer fold)en Allternative nidjt überlegento fteben blieb, jonbern unbedenflid) für bie zweite $\mathfrak{A n t}$ ber Behanb= lung bes Etoffez entidied, bebarf feiner Frörterung. Fin Berf aber, weldes darauf berednet ift, fein Burlifum unter folden Bebilbeten zu finben, welde bie mifrojfopifde foridung mebr vom פörenjagen, als 


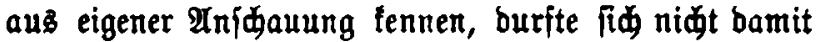
begnügen, bie Thatiaden felbft zu bringen, fonbern muste fid angelegen jein laflen, bem Sejer in fteter fritifder Sidtung unb Beleudtung einen Fübrer mit= zugeben, welder ihn burd bas sabyrintb ber unge= wohnten Singe uno Einorüde binburd fider auj bie Đöbe leitet, von welder auz er bann felbft abrodgent bie Bebeutung bes bebanbelten Mifiensgebietes über= ¡́faut.

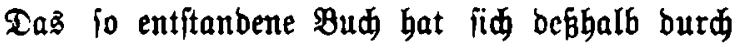

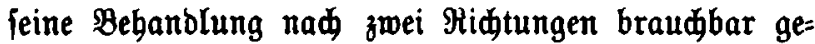
ftaltet. Einmal wirb es bem gebilbeten Laien über= baupt eine $\mathfrak{A}$ nj geben, unb bann wirb es bem Stubirenden ber Ratur= wiाTenidaften, bebor er feine mifrojtopifden Beobadit= ungen beginnt, ein bilf fômittel fein fönren, weldes feine gelanntídaft mit bcm bisher ferne ftebenben Inftrumente permittelt uno bie Einarbeitung in bie ibm neue Foriळungamethobe erleiळtert.

Das vorliegente Berfdien ift bebbalb, weil es aud erniteren Stubien bienen foll, nidt etra aus einigen vorbanbenen Søriften zulammengetragen, fon=

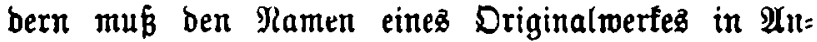
iprud nebmen. Die im geididftliden Theile befino: liḑen Albbiloungen fint fämmtlid, jomeit es überbaupt beute, wo jo viele alte literarifde Shäke idon un= wieberbringlid verloren fint, nod möglid ift, nad photographifden IUufnahmen ber Driginalabbilbungen

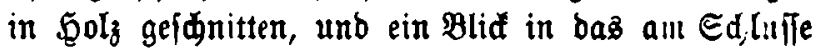


angebängte \&iteraturverzeiøniß wiro bem Lejer fagen, baß Benübung berbeizuidaffen. -

Wenn es̃ nun zmar mein Beftreben war, bem Qejer ein ganz mir felbit eigenes \$uф vorzulegen, fo if

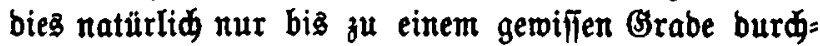
fübrbar. Bei ber Beipređung ber Theorie bes̊ Mifro= ftopes,, wo zumeijt nur burdaus feftftebenbe Säge zu reprobuciren waren, mußte iळ oft auf Riteraturangaben itoßen, bie başjenige, wasి zu jagen war, in ber flarften Weife aubibrültten. So ift bejonberz bas tlaififde Werf von Sarting gerabezu unübertreffliø. Mohl, Dippel u. a. Gaben oft genug vorzügliðe $\mathfrak{A} u s=$ einanberjeşungen gegeben. $23_{0}$ id aljo auf Säze ftieß, weldye ben zu behandelnden Begenitand jo flar

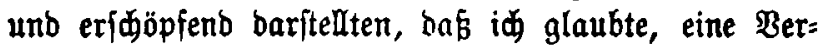

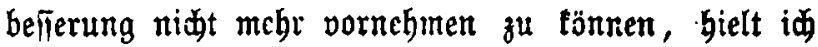

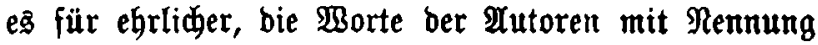
berielben aud̆ ungefdmmälert wieberzugeben, alsె wenn id fie burd einige ftiliftifde Beränberungen bem wahren Eigentbümer entfrembet unb mir felbft nidht zu eigen gemad̆t bätte.

Da bie Mifroffopie feine eigene Mijienl(jaft, foll: bern nur eine Präparationsa = und Foridungämetbobe ift, welde vielen naturmifienidaitlichen Disciplinen gemeinjam zufommt, jo war es nöthig, Streifzüge auf alle mögliden (Bebiete zu unternebmen. Sa nun aber ber 2erfalier ebenlo wenig, wie irgeno ein anberer Forjøer ber heutigen ipecialifirenben $\mathfrak{B i f f e n j}$ aft, alle 


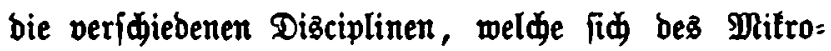
ftopes bebienen, völig beberridt, fo ift zu befürdten, baßs trok allen Strebenz nad unpartbeilidifeit, bod vielleid̆t gar oft bie inbivibuelle fäärbung ber Thier= biftologie zu jebr in ben Borbergrunb tritt. Plöge ber freunbliđe Sejer mit milbem $\mathfrak{u}$ rtheil über folde Mängel binmegieben unb möge er trob̨bem burळ feine Sectutre bie Ueberzeugung gewinnen, bas bas Mifro= ifop ein Injtrument ijt, bem eine univer jelle Bebeutung zufommt! -

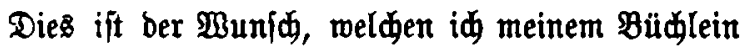
mit auf ben Beg geben mödte.

$\Re$ o it of 